\title{
The usefulness of Gram staining method for analysis of the effectiveness of decontamination of firefighter's protective outfit
}

\author{
Andrzej Polanczyk ${ }^{1, *}$ \\ ${ }^{1}$ The Main School of Fire, Faculty of Fire Safety Engineering, 52/54 Slowackiego St., 01-629 \\ Warsaw, Poland
}

\begin{abstract}
Introduction: This study was undertaken to analyze the effectiveness of different decontamination techniques of firefighters' outfit. Methods and findings: Firefighter's outfit used for one month in field conditions was tested for biological contamination using Gram staining. Biological samples from pantleg above the ankle, on the knee and, in the groin were analyzed. Swabbed places were cut out and sterilized mechanically using tap water, $20 \%$ soap or $70 \%$ ethanol by rubbing for 20 . Swabs were taken before sterilization and right after sterilization. Each time smears were made on sterile glass, fixed in pure ethanol and stained using Gram method. This staining method is used to visualize bacteria and distinguish gram-positive and gram-negative bacteria. After staining samples were air dried and photographed under a light microscope at magnification 100x. Each smear was made in triplicates and the relative number of biological contamination was analysed using ImageJ software. The results indicated that the highest level of contamination was visible on the knee. Decontamination decreased the number of bacteria in all analyzed places right after cloth patch washing. The most effective decontamination fluid was $70 \%$ ethanol followed by $20 \%$ soap. The Gram staining combined with numerical analysis may be successfully used to verify the effectiveness of decontamination method for firefighter's outfit utilized at field.
\end{abstract}

\section{Introduction}

The risk of chemical or biological contamination of firefighters' protective suit during everyday duties is extremally high [1-7]. Application of decontamination process is of significant importance when using particularly hazardous materials including biological contamination [8-12]. This process is carried out by firefighters who undergo special training and are equipped with specialized equipment [13-19]. One of the main task of fire brigades is to decontaminate garments and equipment [20-27] to avoid spreading of potentially biohazardous material among humans and animals.

\footnotetext{
*Corresponding author: apolanczyk@sgsp.edu.pl
} 
Effectiveness of decontamination process is validated using different methods. Among them are biological methods such as staining [28-33], bacterial cultivation [34-36] or dedicated tests [37-39] and equipment [40-43]. Therefore, the aim of this study was to analyze the effectiveness of different decontamination fluids on biological contamination of firefighters' outfit used in field conditions. We also proposed a method of numerical processing of images gathered after staining to validate the effectiveness of decontamination process.

\section{Material and Methods}

\subsection{Samples collection}

Firefighter's outfit used for one month in field conditions was tested for biological contamination using Gram staining [44-47]. Sterile cotton swabs were used to take biological samples from pantleg in three places: above the ankle, behind the knee and, in the groin. Next, swabs places were cut out and sterilized mechanically using tap water, tap water with $20 \%$ soap or $70 \%$ ethanol by 20 seconds rubbing. Swabs were taken in three time point: before sterilization, right after sterilization, and $24 \mathrm{~h}$ and $48 \mathrm{~h}$ after sterilization. Between samples collections cloth patches were kept on sterile open Petri dishes placed on bench at fresh air. Samples were collected in triplicates.

\subsection{Gram staining}

Each time smears were made on sterile glass, fixed in pure ethanol and stained using Gram method. This staining method is used to visualize bacteria and distinguish gram-positive and gram-negative bacterial species. Briefly, in this method samples are stained with crystal violet which joins peptidoglycans in cell wall, iodine which creates complexes with crystal violet, then distained with alcohol which washes out crystal violet-iodine complex from Gram-negative bacteria and finally samples are stained with fuchsin that stains Gramnegative bacteria. After staining samples were air dried and photographed under a light microscope under immersion oil at magnification 1000x. Each smear was made in triplicates. A positive was defined as a positive Gram smear from prestained smears bought from ANALAB. After staining Gram-positive bacteria are purple-blue and Gram-negative bacteria are pink-red.

Quantitative bacteriology was performed using ImageJ software using the "analyse particles" tool after brightness/contrast adjustment [48-50]. The results of post-processing for analysed areas were presented in Fig. 1. 


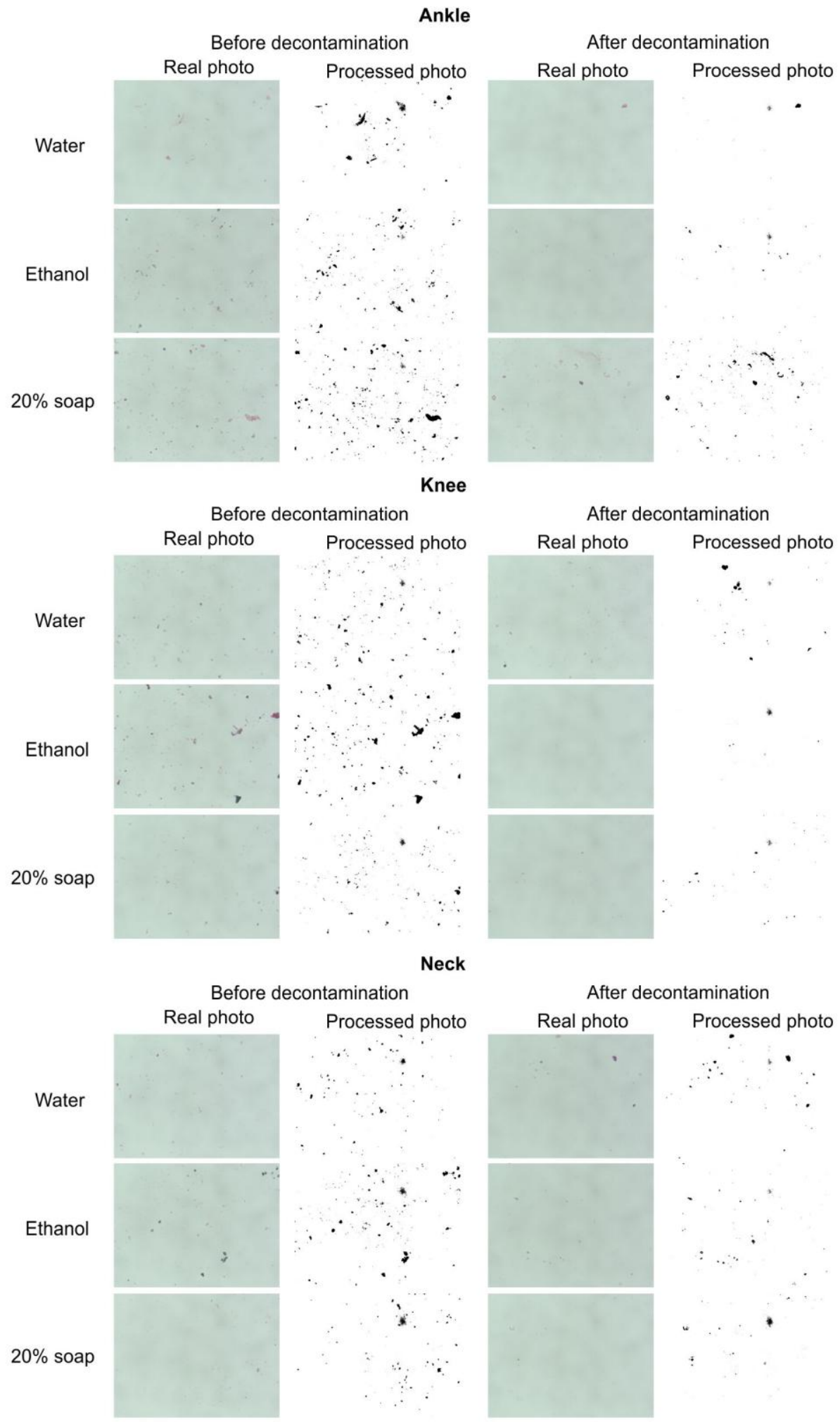


Fig. 1. Representative results of gram method staining (real photo) and processed photographs (black and white) before and after decontamination. Pictures represents results from the ankle, knee and neck areas before decontamination and after decontamination with tap water, $70 \%$ ethanol and $20 \%$ soap. Gram-positive bacteria are purple-blue and Gram-negative bacteria are pink-red in the "real photo" pictures. Debries- large irregular objects, were also visible before decontamination. Post-processing was done with ImageJ software.

\subsection{Statistical analysis}

Data are presented as mean \pm SEM. Comparison between two groups was performed using the unpaired Student's t-test or non-parametric Mann-Whitney U-test for non-normally distributed variables after verification of normality. Outliers were calculated with Grubbs' test (GraphPad Prism software). Data were considered statistically different when $\mathrm{p}<0.05$.

\section{Results}

The results indicated that the most contaminated with biological material was the knee, when both ankle and neck had similar number of counted events $(142 \pm 20$ events on knee vs. $80 \pm 14$ and $81 \pm 12$ events on ankle and neck, respectively; $<<0.05$; Fig. 2). Some organic debris which were much bigger than bacteria, irregular in shape and stained strongly with red or blue dye (Fig. 1), were also stained however, they were excluded from final counting after post-processing.

To validate the usefulness of Gram method staining for determination of the efficacy of decontamination process we used three different solutions: water, $70 \%$ ethanol and $20 \%$ soap solution. Fig. 2 presented the relative number of biological material on the ankle, knee and neck before and $30 \mathrm{~min}$ after decontamination. The results indicated that both $70 \%$ ethanol and $20 \%$ soap solutions significantly decreased the level of biological material on the ankle and knee. The relative event count for the knee dropped from $178 \pm 16$ to $41 \pm 9$ for $70 \%$ ethanol and from $97 \pm 18$ to $42 \pm 5$ for $20 \%$ soap ( $<<0.001$ ). Representative pictures of the Gram staining and the efficacy of decontamination method on the ankle, knee and neck were presented in Fig. 1.

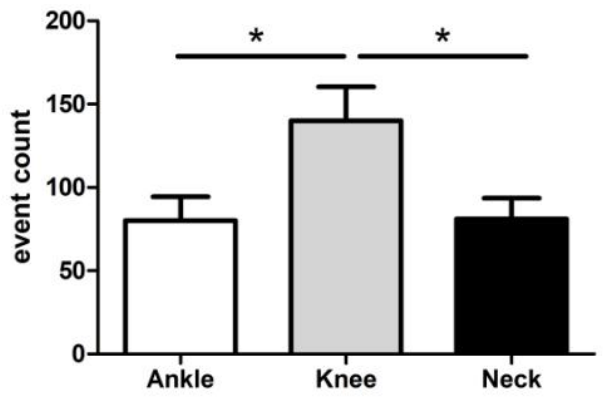

Fig. 2. The relative number of biological contamination on thee exemplary areas of firefighters' suit before decontamination (the ankle, knee and neck). Data are presented as mean \pm SEM. ${ }^{*} \mathrm{p}<0.05$. 

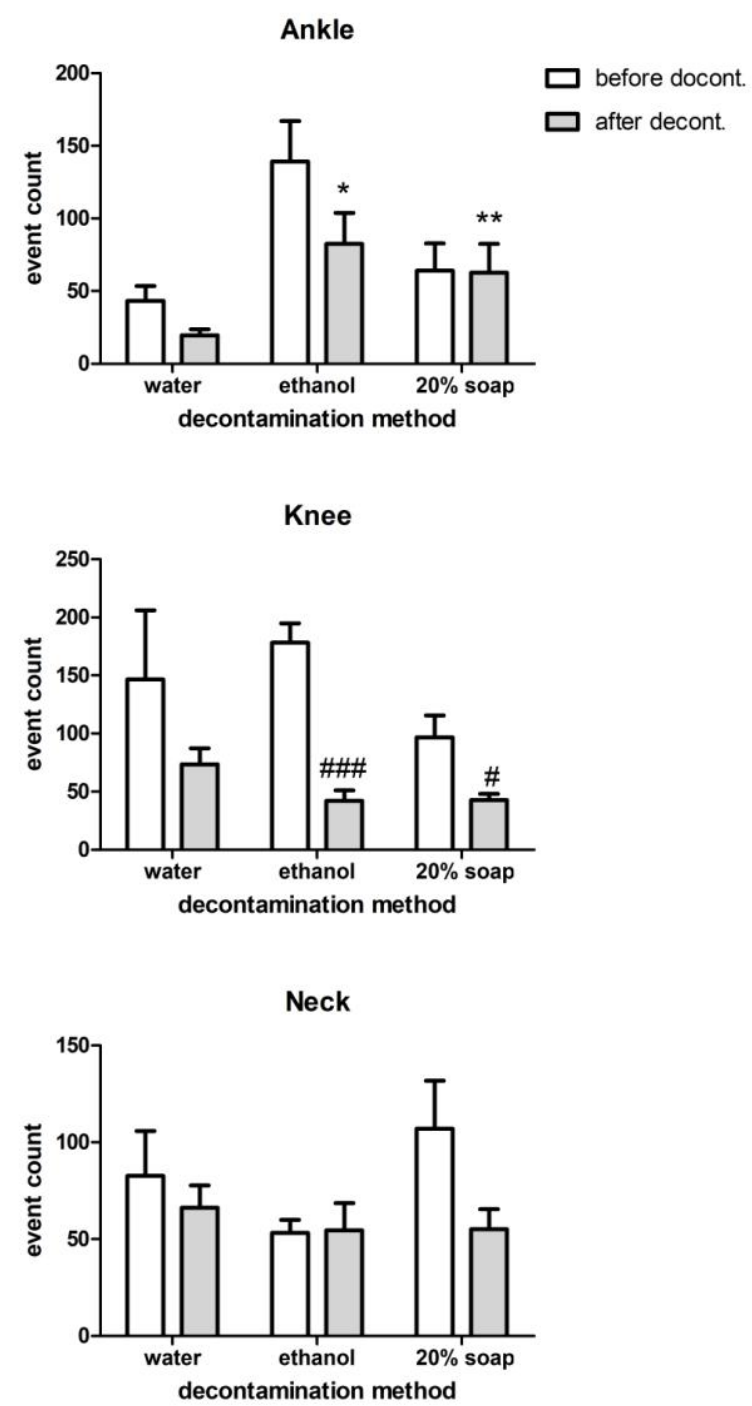

Fig. 3. The relative number of biological material on the ankle, knee and neck before and 30 min after decontamination with tap water, $70 \%$ ethanol and $20 \%$ soap solution. Data are presented as mean

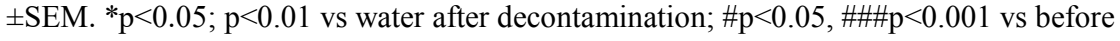
decontamination.

\section{Conclusions}

The Gram staining may be successfully used to verify the contamination level as well as the effectiveness of decontamination method for firefighter's outfit utilized at field. The Gram staining allowed to successfully detect the level of biological material presented on the selected areas of firefighter's garment. We were able to detect bacteria and determine their shape and type of colony formation. Additionally, described method of post-processing of collected pictures enabled quantification of biological contamination. 
The highest number of biological material was detected on the knee after one month of training. The most effective decontamination solution was $70 \%$ ethanol which decreased the level of biological material present on chosen areas of firefighter's outfit by at least $50 \%$. The second effective was soap and the least effective was water.

The described results of samples collection, staining and data-processing indicates that the Gram method may be an easy and effective tool in determination of biological contamination and the efficacy of decontamination.

\section{References}

1. L. Thors, M. Koch, E. Wigenstam, B. Koch, L. Hagglund and A. Bucht, Chem. Bio.1 Interact. 273 (2017)

2. A. Piechota-Polanczyk, A. Kopacz, D. Kloska, B. Zagrapan, C. Neumayer, A. Grochot-Przeczek, I. Huk, C. Brostjan, J. Dulak and A. Jozkowicz, Oxid. Med. Cell. Longev. 2018 (2018)

3. K. Kowalska, D. E. Habrowska-Gorczynska, C. Neumayer, M. Bolliger, C. Domenig, A.W. Piastowska-Ciesielska, I. Huk and A. Piechota-Polanczyk, Acta Biochim. Pol. 65, 1 (2018)

4. B. Petrovsky and E. Monnet, Vet. Surg. 47 (2018)

5. D. Dmochowski, A. Dmochowska, S. Biedugnis, ROS 17 (2015)

6. M. Tytla, A. Dmochowska and D. Dmochowski, E3S Web of Conferences 44, (2018)

7. A. Zieminska-Stolarska, A. Polanczyk, I. Zbicinski, J. Hydrol. Hydromech. 644, 8 (2015)

8. A. Polanczy, T. Wozniak, M. Strzelecki, W. Szubert, L. stefanczyk, Signal Processing SPA 5 (2016)

9. T.M. Osaili, A.R. Alaboudi, H.N. Al-Quran and A.A. Al-Nabulsi, Food Microbiol. 73 (2018)

10. T. Wesierski, M. Majder-Lopatka, R. Matuszkiewicz, R. Porowski, Przem. Chem. 91, 3 (2012)

11. T. Wesierski, M. Majder-Lopatka, W. Wasik, Przem. Chem. 96, 5 (2017)

12. M. Majder-Lopatka, W. Rogula-Kozlowska, W. Wasik, E3S Web of Conferences 44 (2018)

13. A. Polanczyk, M. Podyma, L. Trebinski, J. Chrzastek, I. Zbicinski, L. Stefanczyk, PLoS One 11 (2016)

14. M. Majder-Lopatka and T. Wesierski, E3S Web of Conferences 46 (2018)

15. M. Majder-Lopatka, T. Wesierski, W. Wasik, BITP 42, 8 (2016)

16. M. Polka, Z. Salamonowicz, M. Wolinski, B. Kukfisz, Procedia Eng. 45 (2012)

17. Z. Salamonowicz, W. Jarosz, BITP 3 (2012)

18. Z. Salamonowicz, M. Kotowski, M. Polka, W. Barnat, Przem. Chem. 93 (2014)

19. Z. Salamonowicz, M. Wolinski, M. Sobolewski, M. Polka, Przem. Chem. 93 (2014)

20. Z. Salamonowicz, M. Kotowski, M. Polka, W. Barnat, Bull. Pol. Ac.: Tech. 63 (2015)

21. A. Polanczyk, A. Piechota-Polanczyk, L. Stefanczyk, Plos One 12 (2017)

22. A. Polanczyk, M. Klinger, J. Nonobachvili, I. Huk, C. Neumayer, Appl. Sci. 8, 12 (2018) 
23. A. Polanczyk, M. Strzelecki, T. Wozniak, W. Szubert, L. Stefanczyk, Found. Comp. Decis. Sci. 42, 13 (2017)

24. D. Kloska, A. Kopacz, A. Piechota-Polanczyk, W. Nowak, J. Dulak, A. Jozkowicz and A. Grochot-Przeczek, Vascul. Pharmacol. (2018) [in press]

25. A. Piechota-Polanczyk, A. Goraca, Pharmacol. Rep. 64 (2012)

26. A. Piechota, A. Polanczyk, A. Goraca, Pharmacol. Rep. 63 (2011)

27. A. Piechota, A. Polanczyk, A. Goraca, Pharmacol. Rep. 62 (2010)

28. A. Piechota-Polanczyk, A. Jozkowicz, Curr. Drug. Targets. 17 (2016)

29. A. Polanczyk, Z. Salamonowicz, E3S Web of Conferences 44, 8 (2018)

30. A. Polanczyk, M. Podgorski, T. Wozniak, L. Stefanczyk, M Strzelecki, Medicina 54, 15 (2018)

31. A. Polanczyk, M. Podgorski, M. Polanczyk, N. Veshkina, I. Zbicinski, L. Stefanczyk, C. Neumayer, Interact. Cardiovasc. Thorac. Surg. (2018)

32. A. Piechota-Polanczyk, M. Wlodarczyk, A. Sobolewska-Wlodarczyk, M. Jonakowski, A. Pilarczyk, K. Stec-Michalska, M. Wisniewska-Jarosinska, J. Fichna, Dig. Dis. Sci. 62 (2017)

33. A. Piechota-Polanczyk, M. Zielinska, D. Piekielny, J. Fichna, Biomed. Pharmacother. 84 (2016)

34. A. Polanczyk, A. Piechota-Polanczyk, C. Domenig, J. Nanobachvili, I. Huk, C. Neumayer, Appl. Sci. 8, 14 (2018)

35. M. Salaga, U. Lewandowska, D. Sosnowska, P.K. Zakrzewski, A.I. Cygankiewicz, A. Piechota-Polanczyk, M. Sobczak, P. Mosinska, C. Chen, W.M. Krajewska, J. Fichna, Naunyn. Schmiedebergs Arch. Pharmacol. 387 (2014)

36. D. Dmochowski, A. Dmochowska, S. Biedugnis, ROS 17 (2015)

37. A. Polanczyk, M. Podyma, L. Stefanczyk, W. Szubert, I. Zbicinski, J. Biomech. 48 (2015)

38. W. Eilenberg, S. Stojkovic, A. Piechota-Polanczyk, C. Kaun, S. Rauscher, M. Groger, M. Klinger, J. Wojta, C. Neumayer, I. Huk, S. Demyanets, Eur. J. Vasc. Endovasc. Surg. 51 (2016)

39. H. Zatorski, M. Salaga, M. Zielinska, A. Piechota-Polanczyk, K. Owczarek, R. Kordek, U. Lewandowska, C. Chen, J. Fichna, Naunyn. Schmiedebergs Arch. Pharmacol. 388 (2015)

40. A. Polanczyk, P. Wawrzyniak, I. Zbicinski, Drying Technol. 31, 10 (2013)

41. P. Wawrzyniak, A. Polanczyk, I. Zbicinski, M. Jaskulski, M. Podyma, J. Rabaeva, Drying Technol. 30, 10 (2012)

42. A. Piechota, A. Goraca, J. Physiol. Pharmacol. 62 (2011)

43. W. Jarosz, Z. Salamonowicz, M. Majder-Lopatka, R. Matuszkiewicz, A. Dmochowska, Przem. Chem. 93 (2014)

44. M. Wlodarczyk, A. Sobolewska-Wlodarczyk, A.I. Cygankiewicz, D. Jacenik, A. Piechota-Polanczyk, K. Stec-Michalska, W.M. Krajewska, J. Fichna, M. WisniewskaJarosinska, J. Gastrointestin. Liver Dis. 26 (2017)

45. M. Salaga, L.V. Blomster, A. Piechota-Polanczyk, M. Zielinska, D. Jacenik, A.I. Cygankiewicz, W.M. Krajewska, J.D. Mikkelsen, J. Fichna, J. Pharmacol. Exp. Ther. 356 (2016) 
46. A. Piechota-Polanczyk, S. Demyanets, O. Nykonenko, I. Huk, M. Mittlboeck, C.M. Domenig, C. Neumayer, J. Wojta, J. Nanobachvili, M. Klinger, Eur. J. Vasc. Endovasc. Surg. 45 (2013)

47. A. Polanczyk, M. Podyma, L. Stefanczyk, I. Zbicinski, Chem. Eng. Process. 33, 9 (2012)

48. Z. Salamonowicz, R. Makowski, E3S Web of Conferences 44 (2018)

49. P. Wawrzyniak, M. Podyma, I. Zbicinski, Z. Bartczak, A. Polanczyk, J. Rabaeva, Drying Technol. 30, 9 (2012)

50. Z. Salamonowicz, M. Majder-Lopatka, BITP 30 (2013) 